\title{
The Establishment and Application of Human Body Model of Econopower Car Driver Based on CATIA
}

\author{
Luo Jin, Ma Qihua, Luo Yiping \\ Faculty of Automotive Engineering, Shanghai University of Engineering and Science, Shanghai, China
}

Email address:

84276661@qq.com (Luo Jin),mqh0386@163.com (Ma Qihua), lyp777@sina.com (Luo Yiping)

To cite this article:

Luo Jin, Ma Qihua, Luo Yiping. The Establishment and Application of Human Body Model of Econopower Car Driver Based on CATIA. Communications. Vol. 3, No. 5, 2015, pp. 115-119. doi: 10.11648/j.com.20150305.16

\begin{abstract}
The model of the human body as an important tool of ergonomics, play an important role in the ergonomics research. To deal with the lack of Chinese human body model in CATIA V5, based on the photographic method and the direct measurement method to get the 36 static body size body which parameterized modeling and econopower cars driving posture prediction simulation, and based on this, set up a complete human body model data file of econopower car drivers, import it into CATIA Human Measurement Editor module completed the establishment of human body model of econopower cars driver, and on the basis of the human body model, carried on the brief discussion of its application in the major field of econopower car.
\end{abstract}

Keywords: Ergonomics, Body Model, CATIA, Econopower Car

\section{Introduction}

The human body model is the basis of ergonomics analysis tool. It has a simple ergonomics relationship analysis model of the human body in CATIA V5, the human body model can be associated with human body data in software, create conditions for building digital three-dimensional human body model.

To suit the efficiency analysis of different ethnic groups, there are six different human body model totally in CATIA V5 software, respectively is the United States, Canada, France, South Korea, Japan and Chinese Taiwan. But there is no Chinese human body data, designers can only analyse and evaluate the ergonomics in Chinese use human body model of South Korea or Japan instead of Chinese, so it will obtain unreasonable analysis results. What's more, because of the particularity of econopower cars, it can't meet the needs of all people and selecting the driver with figure as thin as possible, the existing human body model in CATIA V5 is not suitable as the driver body model of econopower car, so before the ergonomics optimization for econopower car, it is important to construct driver body model for econopower cars.

\section{Measuring the Human Body by Photo Size Experiment Method}

Human form measurement data determines the minimum of the cab interior space, the size of the entrances and exits, the height of the seat, etc. The latter is the range of motion can be achieved of a driver's trunk or limbs, it determines the position of the control in the cab, etc. In the design of econopower cars, if you want to make drivers would be able to finish the race, the first thing to consider is the human body size and scope of applicable people.

\subsection{Experimental Equipment and Experimental Measurement Methods}

Laboratory equipment: digital camera, a tripod, benchmarking walls, steel rule (precision: $1 \mathrm{~mm}$ ), chair, marker pen.

\subsection{Anthropometric Datum Point}

The measurement used some of the main body size:

Above head point: the point is located in the center of the body line at the top of the highest point.

Tip of the finger points: longest finger of average person, so choose the top of the middle finger.

Shoulder point: the starting point of arm and upper arm which located in the edge of shoulder.

Nipple point: used to determine the point of the chest height, its location is respectively in the human body chest around the top, it is better to recognize.

Cervical point: refers to the junction point of the central neck and back. 
Elbow point: the most outstanding point when elbow bend, it is also the most salient points at the top of the ulna.

Umbilical point: the point which make sure the waist high, the center of the navel.

Knee point: the center of the knee.

\subsection{Anthropometric Datum plane}

In the human body measurement, generally consists of three mutually perpendicular axis including vertical axis and horizontal axis to locate the anthropometric datum plane.

The median sagittal plane, is the most special one in sagittal plane, it is just divided people into two symmetry parts including the left and right.

Horizontal plane, divided the human body into two parts of upper and lower, all plane are vertical with coronal and sagittal, namely is parallel with the plane where location of sole.

Coronal, vertical axis and the horizontal axis two axis line in the plane, divides the body into before and after two parts, including all of the parallel plane.

\section{Using CATIA to Establish Driver Body Model of Econopower Car}

\subsection{The Selection of Human Body Size Data}

Table 1. The selection of human body size data.

\begin{tabular}{|c|c|c|c|}
\hline $\begin{array}{l}\text { Dimension } \\
\text { code }\end{array}$ & Dimension name & $\begin{array}{l}\text { Dimension } \\
\text { code }\end{array}$ & Dimension name \\
\hline Us100 & Height & Us31 & Standing neck height \\
\hline Us3 & $\begin{array}{l}\text { Standing shoulder } \\
\text { height }\end{array}$ & Us7 & Axillary height \\
\hline Us38 & $\begin{array}{l}\text { Standing chest } \\
\text { height }\end{array}$ & Us 120 & Waist height \\
\hline Us39 & $\begin{array}{l}\text { Standing hip } \\
\text { height }\end{array}$ & Us 73 & Standing knee height \\
\hline Us5 & Upper arm length & Us88 & Forearm length \\
\hline Us60 & Hand length & Us61 & Head width \\
\hline Us69 & $\begin{array}{l}\text { Interpupillary } \\
\text { distance }\end{array}$ & Us33 & Chest width \\
\hline Us113 & Waist width & Us66 & Standing hip width \\
\hline Us51 & Feet width & Us94 & Sitting height \\
\hline Us50 & Sitting eye height & Us 122 & Sitting waist height \\
\hline Us63 & Head length & Us76 & Ankle height \\
\hline Us2 & Sitting waist thick & Us4 & $\begin{array}{l}\text { Sitting shoulder } \\
\text { height }\end{array}$ \\
\hline Us92 & $\begin{array}{l}\text { Shoulder elbow } \\
\text { distance }\end{array}$ & Us74 & Sitting knee height \\
\hline Us13 & $\begin{array}{l}\text { Maximum } \\
\text { shoulder width }\end{array}$ & Us28 & Hip leg distance \\
\hline Us52 & Foot length & Us11 & Shoulder width \\
\hline Us27 & Hip knee distance & Us 70 & Back width \\
\hline Us67 & Sitting hip width & Us79 & $\begin{array}{l}\text { Sitting middle } \\
\text { shoulder height }\end{array}$ \\
\hline Us93 & Shoulder length & Us73 & Knee middle height \\
\hline
\end{tabular}

This article selects the 36 static body dimension which human body required for parametric modeling and driving posture prediction simulation as quick photographic measurement research goal. According to the access method, the size are divided into two categories: 1) the size of the measured directly by measuring instrument; 2) the size of the measurement is obtained by photographic method. The corresponding measuring project code, classification and meanings are shown in table 1 .

\subsection{Human Model File Format Requirements in Catia}

Create a new model of the human dimension that can be used to be model data file must follow a certain form. A crowd file contains four sections, using the four groups of key words:

MEAN STDEV M( )-This section lists the dimensions of the male parts

MEAN STDEV F ( ) - This section lists the dimensions of the female parts

CORR M( ) - This section lists the numerical values of the correlation among the dimensions of the male parts.

CORR F( ) - This section lists the numerical values of the correlation among the dimensions of the female parts.

The 4 paragraphs are selectable, the first key word represent the average size of male and standard deviation, the second represent the average size of female, but one of the two is must.

In the option of "MEAN STDEV", needed to provide each measurement values of econopower car driver body size, including mean and standard deviation, each item occupied a line and describe a variable with the way of $<$ variable $><$ mean $><$ standard deviation $>$. The average system default should be centimeter as the unit, the datum of standard deviation is built on the basis of the centimeter unit.

The optional of "CORR" represent the body size dependency, it need to fill out the correlation coefficient between the dimension code and which correlation coefficient expressed the mutual dependence between the two variables, the optional of "CORR" is dispensable, it only affects the model accuracy. Among them, STDEV MEAN must be written in front of the CORR. The writing format is as follows: $<$ variable $1><$ variable $2><$ correlation $>$.

$<$ Variable $1>$ here is the reference number of first variable, $<$ variable $2>$ is the reference number of second variable, the correlation is the correlation value that link the two variables together, it need to pay attention is the variable 1 must be different from variable 2 , because according by the definition, the correlation of a variable and itself is 1.0,in addition, a variable reference number must be smaller than the number of variables 2 reference. Correlation must be within the range of the $-1.0 \sim 1.0$, if the given correlation values are not within the range of $[-1.0,1.0]$, the error will occur.

It is simple to calculate the number of < variable $><$ average $><$ standard deviation $>$, through the excel built-in function will quickly obtains the corresponding mean and standard deviation. The difficulty lies in the optional of CORR. The correlation of each human body size, some correlation is very high and the other is relatively low.

At last, the MEANSTDEV and CORR data are recorded in the notepad file, and change the file property of txt to SWS format, and then named as A1.sws. In the CATIA tools drop-down menu, select options, in the options dialog box to customize the crowd column above the right click the "Add" 
button, selectA1.sws, the file will be read smoothly, the appropriate human model A1 will add to the list. After the success of the human body model file, we can establish the corresponding human model.

\subsection{Establish a New Model of the Human Body Size Data File}

\subsubsection{Human Posture While Measurement}

Upright posture: The testee lift up the head, head positioning through eye ear plane, eyes look straight ahead, relax the shoulders, arms drooping naturally, unbend the arms, palm toward the side of the body, fingers lightly attached on the side of the thigh, knee naturally unbend, put left and right foot heel together, separate the front end, make the feet represent 45 degree angle roughly and make the weight distribution in two feet. In order to make sure that the upright posture is correct, the testee should be make the heel, the buttocks and the back part contact with the same vertical lead.

Sitting posture: The testee sitting lift up the head in the plane that adjusted to the height of the fibular head and head positioning through eye ear plane, eyes look straight ahead, left and right thigh roughly parallel and knee flexion is a roughly rectangular, feet placed on the ground, hands on his lap gently. Make sure the correct posture that the testee's buttocks, back should be simultaneously on the same vertical lead.

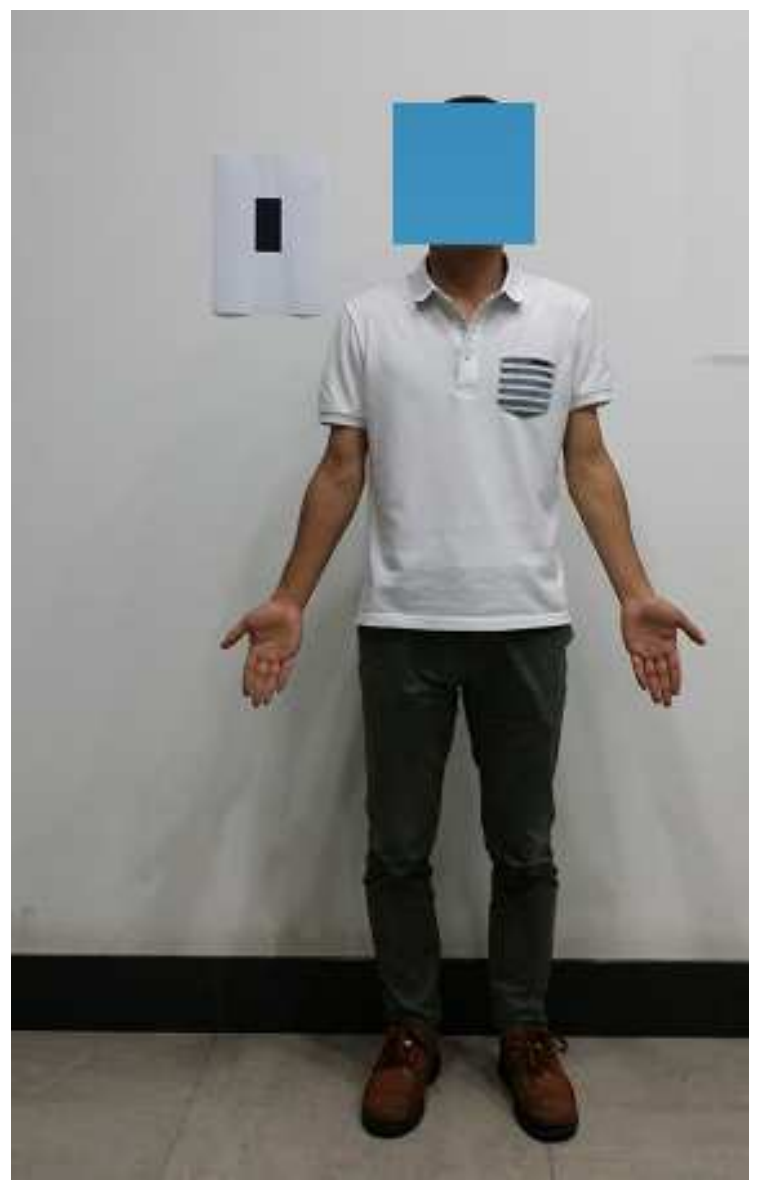

Fig. 1. Photographic method.

\subsubsection{Measurement of Body Size by Photographic Method}

Using software of Coreldraw12.0 to measure body size on photos, according to the benchmarking scaling, through the recognition of the human dimension direct or indirect measure the size of various parts of the body, finally get the main body size.

Proportional conversion formula:

Human height $=$ (measured by the human size of the pixel length / the pixel length of benchmarking) ${ }^{*}$ the actual length of benchmarking (Unit: mm)

\subsection{Determination of Correlation Coefficient}

The correlation coefficient of two parameters mainly by the following formula:

$$
\gamma_{X Y}=\frac{\sum_{i=1}^{N}\left(X_{i}-\bar{X}\right)\left(Y_{i}-\bar{Y}\right)}{\sqrt{\sum_{i=1}^{N}\left(X_{i}-\bar{X}\right)^{2}} \sqrt{\sum_{i=1}^{N}\left(Y_{i}-\bar{Y}\right)^{2}}}
$$

\section{Application of the Human Body Model in the Interior Layout of the Econopower Car's Driving Room}

\subsection{Frame Design of Econopower Car}

During the process of the frame design, for the purpose of reducing the fatigue level of driving and riding, the design must be meet the requirements of human comfort. To meet the frame and the human body attached to the sense of comfort, improve the driving comfort, the design of the frame must be accord with the principle of ergonomics, therefore, the frame design of econopower should not only have to be in good shape, but also make the shape curve to conform to the request ofergonomics.

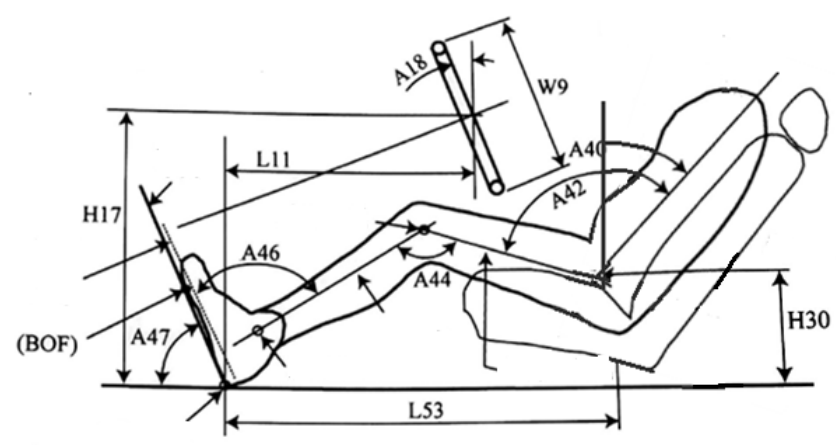

(AHP)

Fig. 2. The angle of of human body model.

In CATIA V5, it can to positioning all kinds of shape of human body model according to the comfortable angle of joints, accurately design the angle of the frame and the is width and height of back. The angle of the greater influence on 
the comfort of human body model as shown figure 2 , from the comfort of human body model angle values as shown table 2 , according to the basic size of the human body model, design the econopower's frame as shown figure 3 .

Table 2. The comfort of human body model angle values.

\begin{tabular}{|c|c|c|c|c|c|}
\hline Parameter code & Parameter name & $\begin{array}{l}\text { Empirical } \\
\text { reference value }\end{array}$ & Impact on comfort & $\begin{array}{l}\text { Correlation } \\
\text { dimension parameter }\end{array}$ & $\begin{array}{l}\text { Recommended } \\
\text { value }\end{array}$ \\
\hline A42 & Angle of body leg & $95^{\circ} \sim 120^{\circ}$ & $\begin{array}{l}\text { Too large or too small will cause thigh } \\
\text { uncomfortable }\end{array}$ & Back angle & $100^{\circ}$ \\
\hline A 40 & Back angle & $25^{\circ} \sim 60^{\circ}$ & $\begin{array}{l}\text { Too large will cause thigh uncomfortable, } \\
\text { too small will case shoulder uncomfortable }\end{array}$ & Back angle & $60^{\circ}$ \\
\hline A44 & $\begin{array}{l}\text { Angle of thighs and } \\
\text { leg }\end{array}$ & $95^{\circ} \sim 135^{\circ}$ & $\begin{array}{l}\text { Too large or too small will cause leg } \\
\text { uncomfortable }\end{array}$ & $\begin{array}{l}\text { The horizontal distance } \\
\text { between } H \text { point and } \\
\text { AHP point }\end{array}$ & $120^{\circ}$ \\
\hline A46 & $\begin{array}{l}\text { Angle offeet and } \\
\text { leg }\end{array}$ & $85^{\circ} \sim 110^{\circ}$ & $\begin{array}{l}\text { Too large will cause feet uncomfortable } \\
\text { too small will case leg uncomfortable }\end{array}$ & $\begin{array}{l}\text { The vertical distance } \\
\text { between the } \mathrm{H} \text { point } \\
\text { and the AHP point }\end{array}$ & $90^{\circ}$ \\
\hline A47 & Pedal angle & $55^{\circ} \sim 85^{\circ}$ & $\begin{array}{l}\text { Too large or too small will cause leg and feet } \\
\text { uncomfortable }\end{array}$ & & $67^{\circ}$ \\
\hline
\end{tabular}

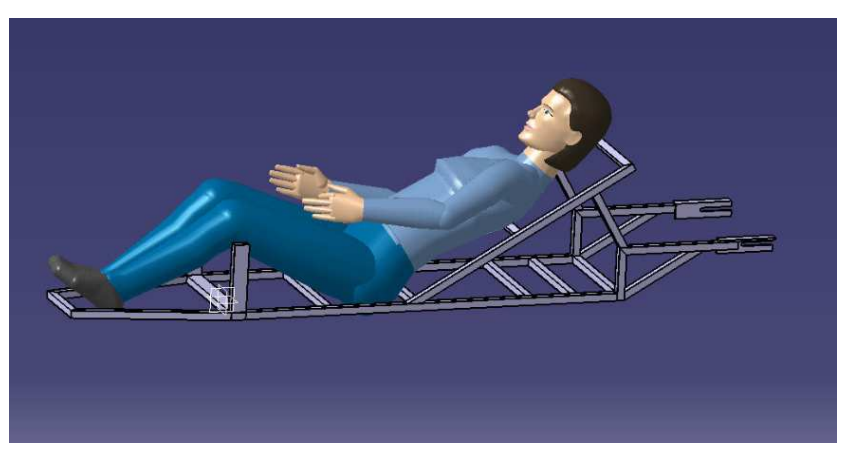

Fig. 3. Design the econopower's frame.

\subsection{Application in Field of Vision}

$80 \%$ of information is obtained by the driver's vision when drive the econopower car, so the driver's visual channel is the most important traffic message channel, the human body model of econopower car driver have good evaluation effect on optimization design of driver's field vision. The driver's vision can be summarized as front view, the car's visual field, rear view and both sides of the visual field. Front view of the driver mainly includes the observation of the front road and the observation of various control instruments and other related field of view.

Eyellipse is origin benchmark of econopower car vision performance, also is a major tool of econopower ergonomics design, through the analysis on the driver front view can judge whether the automobile design is reasonable, otherwise it will obtain optimization.

\subsection{Application in the Control Interface}

An important principle in the design of the econopower body is the position of all manual operation button, rod, switch should be in the driver's hand reach envelopes. Driver's hand reach envelopes is refers to the driver in a normal position to sit in the seat, his right foot supporting on the accelerator pedal heel points, one hand holding the steering wheel and the other hand can reach maximum spatial contour surface.

In the course of the competition, the driver is highly concentrated, if the design of the control interface is not reasonable, it will increase the amount of security risk to the driver. Accurate body model of econopower car provides the basis for the design of the driver's control interface.

\section{Conclusion}

Based on the human dimensions of Chinese adults data to update, obtain the more accurate anthropometric data, and then calculate the data of average value and standard deviation, will get a econopower car body size of the driver file, import it into CATIA. Then it will be shown in the New Mankin tab to display the establishment of the driver of the human model in CATIA, and then analyse the application on the frame,econopower car vision and the control interface.

\section{References}

[1] Miriam P. Reed, Carol A. C. Flannagan, Matthew P. Reed Development of an Improved Driver Eye Position Model[J]. SAE Technical Paper 980012.

[2] Zhao yan. Research and development of econopower car and research of technology [D]. Xi 'an: Chang 'an university, 2009.

[3] CATIA V5 Knowledge advisor user's guide, DASSAULT SYSTEMS, 2000.

[4] CATIA Object Manager, Interactive User Access Reference Manual, DASSAULT SYSTEMES.

[5] Dennis Gryp,Bruce Bradtmiller. Anthropometric Study of U.S. Truck Drivers: Methods and Approach[J]. SAE Paper, 2002-01-3107.

[6] Thomas Seitz,Jochen Balzulat, Heiner Bubb. Anthropometry and measurement of posture and motion[J]. International Journal of Industrial Ergonomics, 2000.

[7] GrandjeanE. Sitting Posture of Car Driving From the Point of View of Ergonomics[J]. Human Factors in Transport Research, 1980,18: 33-34.

[8] A.Oudenhuijzen, K.Tan, F.Morsch. The Relationship Between Seat Pressure and Comfort[J]. SAE Paper, 2003-01-2213. 
[9] Liujun, Ren Xuemei, Ma Hongbin. The optimal design of high efficiency and econopower car ignition time [J]. Journal of Beijing technology university, 2013, (6): 586-589.

[10] Wang Xin, Gou Zhibin, Zheng Sizhe, Yan Shiming. Improvement of econopower car engine performance [J]. Journal of Hubei University of Automotive Technology, 2011, 25 (2): 75-80.
[11] Lei Lei. Research of econopower car research technology [D]. Xi 'an: Chang 'an university, 2008.

[12] Matthew P.Reed. Application of Digital Human Modeling to the Design of a Postal Delivery Vehicle[J]. SAE Paper, 2005-01-2675. 